\title{
ENHANCING EMPLOYEE INNOVATION THROUGH CUSTOMER \\ ENGAGEMENT: THE ROLE OF CUSTOMER INTERACTIVITY, EMPLOYEE AFFECT, AND MOTIVATIONS
}

\begin{abstract}
Customer engagement involves customers' interactive experiences with a brand or service provider. Focusing on the hotel industry, this study investigates the role of customer interactivity, positive affect, and employee motivations in enhancing employees' innovative behaviors under the S-O-R (stimulus-organism-response) framework. Using data collected via a mixed-mode quantitative survey of 830 Chinese hotel employees, the authors developed and tested a structural model. The findings suggest that customer interactivity, positive affect, and motivations as influential factors affect employee innovative behavior. Specifically, customer interactivity influences employee innovative behavior directly and indirectly through positive affect, intrinsic and extrinsic motivations. Theoretically, the study clarifies the mechanisms underpinning customer interactivity's effect on employees' innovative behaviors and extends the S-O-R model by applying it in the organizational behavior domain. Practically, the results highlight a need for reward systems to incorporate measures of employee performance in relation to fostering customer interactivity and engagement.
\end{abstract}

Keywords: customer interactivity; employee innovative behavior; positive affect; intrinsic motivation; extrinsic motivation; hospitality 


\section{INTRODUCTION}

Customer engagement (CE) "occurs by virtue of interactive, co-creative consumer experiences with a focal agent/object (i.e., a brand) in focal service relationship" (Brodie, Hollebeek, Jurić, \& Ilić, 2011, p. 260). Therefore, customer-employee interactions and value co-creation are theoretically regarded as the root of customer engagement (Brodie et al.,

2011). While much recent research has investigated customer engagement (CE) in the online domain, the traditional offline environment where customers interact directly with a brand through representations of the brand (e.g., service employee and product offerings) is also highly relevant (Alvarez-Milán, Felix, Rauschnabel, \& Hinsch, 2018). However, this development occurs predominantly within the marketing domain, with little effort reflecting an organizational behavior perspective. In particular, few studies have linked CE to service innovation at an individual employee level. Focusing on the hotel industry, this study addresses this neglect by investigating the influence of the interactive aspect of $\mathrm{CE}$ on the innovative behavior of employees, who constitute an important group of internal customers.

Employee innovation in the workplace is of great importance to the effectiveness and survival of an organization (Bani-Melhem, Zeffane, \& Albaity, 2018; Gu, Duverger, \& Yu, 2017; Scott \& Bruce, 1994). It represents a process in which individuals create novel ideas or new problem-solving approaches in their work role and then seek to actualize the ideas (Amabile, 1988), relying on engaged employees and customers for input (Li \& Hsu, 2016a). In the tourism sector, customer interactivity and the feedback it generates help firms create knowledge value through customer engagement (Kumar, Aksoy, Donkers, Venkatesan, 
Wiesel, \& Tillmans, 2010).

Knowledge of employee innovative behavior has been built largely through studies focusing on the manufacturing sectors ( $\mathrm{Li} \& \mathrm{Hsu}, 2016 \mathrm{a}$ ), and employee innovation in service firms differs from that in manufacturing companies (Li \& Hsu, 2016a; Sheehan, 2006). For instance, employee innovation in manufacturing centers on technology, patents, and transactions of property rights (Li \& Hsu, 2016a), whereas innovations in the service industry focus on the importance of front-line employees (Cadwallader, Jarvis, Bitner, \& Ostrom, 2010). Furthermore, organizational expectations of employees to innovate are more prominent in service-dominant firms, where employees often need to exceed job requirements to improve overall service experience to promptly meet customers' demands with more innovative conduct (Bani-Melhem et al., 2018; Ma \& Qu, 2011), making employee-customer interaction a highly relevant aspect of innovative behavior.

Although employees' innovation behavior is a complex concept (Schuhmacher \& Kuester, 2012; Scott \& Bruce, 1994), previous studies have primarily taken a withinorganization perspective, attributing such behavior to internal factors such as organizational commitment (Gu et al., 2017), leadership (Gu, et al., 2017; Pieterse, Van Knippenberg, Schippers, \& Stam, 2010), individual differences (Chen, 2011), work requirements, and perceived equity of the effort-reward system (Janssen, 2001). Research has also found that employee innovative behavior is closely related to job characteristics (Li \& Hsu, 2016a), such as skill variety, job significance, and task autonomy, which can affect employee innovation by influencing their psychological states of work motivation and perceived work meaningfulness (Li \& Hsu, 2016a), and subsequently making employees better at new service 
development and problem solving (Sahu \& Srivastava, 2017). This psychological perspective is another differentiating dimension between service and manufacturing, as the latter involves direct impact of customers on employee emotions and behaviors to a much lesser extent. This difference in impact is due largely to the simultaneous production and consumption of services and the highly interactive nature of the service experience, which expose employees directly to the language and behavior of customers, creating more emotional interactions in the service industry than in the manufacturing sector (Ryu \& Lee, 2017).

As service innovations will ultimately be judged by customers (Slåtten \& Mehmetoglu, 2011), collaboration with customers can be a key source of innovative concepts and ideas (Kumar et al., 2010; Li \& Hsu, 2018) as well as a value co-creator (Li \& Hsu, 2018). In the general context of new product development and innovation, studies investigating the mechanisms underlying customer interaction's influence have often taken the perspectives of resource dependence (Gruner \& Homburg, 2000) and knowledge integration (Foss, Laursen, \& Pedersen, 2011; Schaarschmidt, Walsh, \& Evanschitzky, 2018). These studies have generated useful insights into product co-creation but have not sufficiently explained the relationships between employee-customer interaction and service innovation (Li \& Hsu, 2016a; Ma \& Qu, 2011). Earlier studies have also attributed the effect of employee-customer interaction to its ability to engage individuals in a cognitive process (e.g., Liu \& Shrum, 2002). More recently, scholars have investigated the relevance of other factors such as psychological states (Li \& Hsu, 2016a; Ohly \& Fritz, 2010) and motivational factors such as the effort-reward system (Janssen, 2001). Despite evidence that psychological states may affect employee motivation (Li \& Hsu, 2016a; Ohly \& Fritz, 2010), the roles of these 
factors have been investigated in separate studies, and thus the interplay of these factors to jointly influence employee innovative behavior remains unclear.

In the field of tourism and hospitality, recent studies have examined employees' innovative behaviors. Li and Hsu (2016a) present a comprehensive review of the literature on employee innovative behavior in the service industry, summarizing its conceptualization and operationalization and suggesting the clarification of customer participation and customer exchange's roles as worthwhile research directions. Li and Hsu (2018) focus on customer participation (a more one directional from customer to employee construct) and suggest that affective trust mediates the effect of customer participation on employee innovative behavior, highlighting affect's relevance to employee innovation research. In contrast, Li and Hsu (2016b) investigate the role of customer-employee exchange. While interactivity emphasizes the bidirectional nature of interaction (Bonner, 2010), customer exchange emphasizes customers' consideration of costs and benefits (Li \& Hsu, 2016b), implying different motivational emphasis of the two constructs. Their study reveals that the effect of customeremployee exchange was partially mediated through the social psychological climate for innovation - that is, employees' perception of the support and resources provided by customers rather than those provided by organizations. The study does not consider the desire of individual employees for innovation.

Despite these efforts, empirical academic research of employee-customer interactivity has been limited (Bonner, 2010; Schaarschmidt et al., 2018). Previous research has focused on either firm-level parameters (Pieterse et al., 2010) or employee aspects such as job stress and workplace happiness (Li \& Hsu, 2018) rather than interactions between customers and 
employees, especially in a hospitality and tourism context. This study differs from previous studies by emphasizing customer interactivity as two-way interaction instead of one-way participation and by focusing on the innovators (i.e., employees) and their innate needs, motivations, and feelings. By highlighting service interaction as a psychological phenomenon, this research provides more depth and breadth in the understanding of the customer-employee relationship. Drawing on the stimulus-organism-response (S-O-R) framework (Mehrabian \& Russell, 1974), this study proposes a conceptual model of the customer interactivity-employee behavior relationship and tests the model on a sample of 830 customer-contact hotel employees in China.

\section{LITERATURE REVIEW AND HYPOTHESES DEVELOPMENT}

Theoretical Framework: The Stimulus-Organism-Response Framework

The S-O-R framework posits that the external environment contains material and social stimuli (S) that can affect an individual's internal state or organismic response such as emotion, motivation, attitude, and reasoning $(\mathrm{O})$, subsequently leading to behavioral responses (R) (Mehrahian \& Russell, 1974). In the hospitality context, the S-O-R framework has been considered useful for exploring the relationship between service provision and guests' behavior (Jang \& Namkung, 2009), focusing on predominantly customer response to the service environment (e.g., ambiance and atmosphere) and service mode (e.g., self-service) (Ahn \& Seo, 2018; Jani \& Han, 2015).

In the present study, we utilize the S-O-R framework to investigate how customeremployee interactivity affects employee innovative behavior. Customer-employee interactivity (S) acts as an external factor in the service environment that stimulates an 
employee's innovative reaction (R) (Li \& Hsu, 2018) through the mediators of positive affect and motivations $(\mathrm{O})$. This conceptualization aligns with previous suggestions of interactivity as a social stimulus in the service environment (Choi \& Kandampully, 2019; Jani \& Han, 2015; Hew, Leong, Tan, Lee, \& Ooi, 2018) and the research framework proposed by Li and Hsu (2016a), which summarizes the relationship between job characteristics and employee innovative behavior, asserting that employees' motivational and emotional states are important mediators of this relationship. However, the mediation role of emotion has not been empirically verified (Li \& Hsu, 2016a). Similarly, there has been a lack of investigation into the role of motivation, with few exceptions (e.g., Coelho, Augusto, \& Lages, 2011; Hon,2012; Cadwallader, Jarvis, Bitner, \& Ostrom, 2010; Gumusluoglu \& Ilsev, 2009), which focus on only intrinsic motivations.

\section{Customer Interactivity and Employee Innovative Behavior}

In a hotel setting, customer-employee interactivity can act as a stimulus ( $\mathrm{S}$ in the S-O$\mathrm{R}$ framework) that elicits the employees' reactions. In a broad sense, customer interaction refers to all forms of contact, involvement, and engagement between customers and organizations in the process of value creation. It also includes customers' interaction with the organization and its other customers outside of purchase (Kim \& Baker, 2019; Liu \& Shrum, 2002; So, King, \& Sparks, 2014). As a multi-level concept, interaction can take place between a customer and an enterprise (Foss et al., 2011), a project team within the enterprise (Bonner, 2005; Bonner, 2010), or an individual employee of the enterprise (Fowler \& Bridges, 2012).

While a variety of customer interactivity definitions exist, they generally describe 
interactivity as the degree to which interactions occur in communication between two parties and tend to focus on three distinct aspects of interactivity: bidirectionality (reciprocal communication), participation, and joint problem-solving. Within the service encounter, communication between employees and customers are reciprocal rather than linear (Solomon, Surprenant, Czepiel, \& Gutman, 1985) where information is communicated and analyzed and feedback is provided (Liu, 2003), a feature labeled bidirectionality (Bonner, 2010; Mohr \& Nevin, 1990). Another feature of customer interactivity, participation, refers to customers' active and direct participation in service development (Bonner, 2010). For example, through complaints and feedback, customers inform hotel employees of problems so corrective actions can be taken (Namkung, Jang, \& Choi, 2011). Customer participation also yields significant innovative ideas and suggests innovative solutions to service providers. Joint problem solving is another feature of customer interactivity (Bonner, 2010), as when dissatisfied customers become engaged in addressing the issues of customer retention and product design. In this study, we adopt this three-dimensional conceptualization of customer interactivity to explore its effect on employee innovative behaviors.

Studies of web interactivity (Fortin \& Dholakia, 2005; Sheng \& Joginapelly, 2012) have conceptualized interactivity as a stimulus. It is an important social stimulus in webbased advertising (Fortin \& Dholakia, 2005) that influences attitudes and purchase intention through stimulating physiological arousal. In online stores, interactivity is an important atmospheric cue that stimulates consumers' cognitive and emotional state, and subsequently their behavioral response (Sheng \& Joginapelly, 2012). In addition, interactivity also acts as a stimulus in an off-line environment, that is, a social impact that affects behavioral responses 
through psychological influences (Attiq, 2015).

Employee innovative behavior represents the behavioral response component $(\mathrm{R})$ in the S-O-R model. Innovative behavior of front-line staff provides novel solutions for customers during the service process, which is to a large extent linked to the customization of services (Slåtten \& Mehmetoglu, 2011). As employees can hardly achieve personalized service without a full appreciation of customer needs and demands, much innovative behavior consists of joint activity involving customers (Ma \& Qu, 2011). Interactions between front-line employees and customers is a rich source for innovative thinking (Lai, Hon, \& Lui, 2014; Schaarschmidt et al., 2018), as it promotes information and knowledge sharing between the two parties, enabling greater understanding of customer needs and preferences and fostering more inspired and innovative solutions (Cui \& Wu, 2016). In particular, the bidirectional nature of interactivity allows for a process of modifying and improving ideas and solutions on the basis of feedback from both sides (Bonner, 2010). Customers' active participation in the problem-solving process can also bring knowledge beyond organizational boundaries and may result in solutions that had not occurred to the employee (Nieves, Quintana, \& Osorio, 2014). Moreover, as the nature of two-way interactivity is purposive as well as task- and goal-oriented, the accuracy and smoothness of communication improve (Bonner, 2010). Therefore, we hypothesize:

$\mathrm{H1}_{0}$ : Customer interactivity is not related to employee innovative behavior.

$H 1_{a}$ : Customer interactivity is positively related to employee innovative behavior.

\section{Customer Interactivity and Positive Affect}

Positive affect reflects the "extent to which a person feels enthusiastic, active, and 
alert" (Watson, Clark, \& Tellegen, 1988, p. 1063), and can be measured as either a trait or a state. As a trait, positive affect "predisposes people to experience positive emotions and moods as well as to have a positive outlook and orientation" (George \& Brief, 1992, p. 318). As a state, positive affect is more transient and captures how one feels at a particular time or situation (George \& Brief, 1992). We regard positive affect as an induced feeling state that can facilitate flexible thinking, enable effective problem solving, and enhance performance (Aspinwall, 1998; Isen \& Reeve, 2005). In the S-O-R paradigm, positive affect is considered an organism component $(\mathrm{O})$, explaining the mechanism for how customer interactivity evokes employee's behavioral response.

Most studies on affective states focus on negative emotion and affect (e.g., depression, boredom, emotional exhaustion) resulting from interactions (Lee \& Ok, 2012). However, interactions also generate positive emotions because employees have the opportunity to gain professional recognition, experience career development, even find fun and excitement in interacting with customers (Slåtten \& Mehmetoglu, 2011). Studies have suggested that social contact, such as a pleasant interaction with a customer, would likely generate feelings such as encouragement, happiness, and delight, contributing positively to employees' psychological well-being (Barnes, Ponder, \& Hopkins, 2015). From the perspective of social interactivity, when employees perceive that customers are actively involved in problem solving and innovation, they expend effort in adjusting their own emotional state and behavior to cope with the situation (Kiffin-Petersen, Murphy, \& Soutar, 2012). In addition, active communication results in effective feedback and brings about new ideas, and makes it easier for employees to perform tasks (Li \& Hsu, 2018). Therefore, 
cooperation from customers may relieve employees' role pressure, producing a positive impact on their emotional states. On the basis of the above discussion, we propose:

$H 2_{0}$ : Customer interactivity is not related to employee positive affect.

$H 2_{a}$ : Customer interactivity is positively related to employee positive affect.

\section{Customer Interactivity, Positive Affect, and Motivations}

In the S-O-R framework, organism, as mental states and mental processes, may refer not only to positive affect but also motivations (Buxbaum, 2016), which can be classified into two categories: intrinsic and extrinsic. Intrinsic motivation is the impetus to engage in a task for its own sake — out of interest and/or enjoyment—and not merely as a means to another reward, whereas extrinsic motivation impels individuals to engage in the work for an independent result (Deci \& Ryan, 1985). Intrinsically motivated people look for pleasure and inherent satisfaction derived from completing a task (Deci, 1975), but extrinsically motivated people focus on goal-driven reasons, such as financial rewards or benefits earned from performing an activity (Deci \& Ryan, 1985). Together, extrinsic and intrinsic motivation influence individuals' intentions regarding an activity as well as their actual behaviors (Deci, 1975).

Intrinsic and extrinsic motivation are inseparable, and for a given task, the two motivations can coexist in an individual (Kuvaas, Buch, Weibel, Dysvik, \& Nerstad, 2017). Individuals will be extrinsically motivated to make efforts if they predict their efforts will lead to good outcomes (Vroom, 1964). Customer interactivity can be seen as a value cocreation strategy aimed at ensuring access to key information, resources, and opportunities related to innovation (Cui \& Wu, 2016; Gruner \& Homburg, 2000) and leading to good 
performance, recognition, and rewards. Employees are likely to become more extrinsically motivated at work when they judge that the activity will generate valued rewards (Cadwallader et al., 2010). In contrast to extrinsic motivation, intrinsic motivation is related primarily to the pleasure and satisfaction inherent in an activity or task (Deci, Connell, \& Ryan, 1989). Social environment and social support can have a significant impact on people's intrinsic motivation level (Deci \& Ryan, 2000). For hotel employees, such social support comes not only from leaders and colleagues but also from customers (Teng \& Barrows, 2009). Interacting with customers offers opportunities to explore and understand new things (Cadwallader et al., 2010), evoking employees' sense of happiness, satisfaction, and delight (Barnes et al., 2015). Interaction also satisfies employees' desire for problem-solving (KiffinPetersen et al., 2012), trust, and recognition from others (Li \& Hsu, 2018), strengthening employees' motivation for work.

The literature posits that work motivation is a psychological process that is predicted by emotion and affect when an individual is in a social relationship (Sahu \& Srivastava, 2017). Positive affect, as a subjective psychological phenomenon, magnifies current experience and perception, and accelerates the level of motivation to trigger action, such as increasing the valence of moderately desirable rewards or interest in and enjoyment of tasks (Isen \& Reeve, 2005). Employees with positive affect are also more likely to be motivated to provide enjoyable products and services (Kahn \& Isen, 1993). Therefore, positive affect plays a central role in enhancing employees' intrinsic (Barnes et al., 2015; Isen \& Reeve, 2005) and extrinsic motivations (Isen \& Reeve, 2005). On this basis, we hypothesize that

$H 3_{0}$ : Customer interactivity is not related to (a) intrinsic motivation and (b) extrinsic 
motivation.

$H 3_{a}$ : Customer interactivity is positively related to (a) intrinsic motivation and (b) extrinsic motivation.

H40: Positive affect is not related to (a) intrinsic motivation and (b) extrinsic motivation.

$H 4_{a}$ : Positive affect is positively related to (a) intrinsic motivation and (b) extrinsic motivation.

\section{Motivations and Employee Innovative Behaviors}

Research suggests that intrinsic motivation has a positive effect on individuals' innovative behavior. Amabile's (1993) model of motivational synergy suggests a connection between intrinsic motivation and individual creativity. In the context of hospitality, intrinsic motivators such as an employee's interest in tasks, feelings of accomplishment, and personal development may closely relate to the employee's innovative behavior (Gumusluoglu \& Ilsev, 2009). Hotel employees who regard their job as meaningful and anticipate accomplishment through good performance tend to take more responsibility and make full use of their abilities (Chiang \& Jang, 2008). Thus, these employees are more likely to innovate and to effectively solve problems (Bani-Melhem et al., 2018). Researchers also suggest that intrinsic motivation enables employees to be more attentive and dedicated to creative tasks, facilitates their exploration of new pathways, and encourages risk-taking (Coelho et al., 2011).

Extrinsic motivations are also related to employee creativity (Amabile, Hill, Hennessey \& Tighe, 1994) and facilitate innovative behavior (Chiang \& Jang, 2008), and 
employees will be motivated to work harder at new service development behavior if the perceived benefits equal or exceed the costs in terms of effort (Kelly \& Thibaut, 1978). External factors (e.g., money, recognition, competition) constrain what people think and do (Deci et al., 1989), and external regulation can be transformed into extrinsic motivation by identifying with a behavior's underlying value (Deci \& Ryan, 2000). Further, through internalization and integration, extrinsic motivation can result in more autonomous motivation or regulatory orientations (Deci \& Ryan, 2000). For example, individuals who appreciate the importance of regular exercise to health will exercise more willingly. Hotel employees' needs for the extrinsic aspects of life, such as rewards, feedback, and recognition, are more prominent in a work condition of intensive labor, low pay, and low social status (Putra, Cho, \& Liu, 2017). Under these circumstances, employees with a high level of extrinsic motivation are more likely to work hard, engage in their work, develop new skills, and seek novel solutions when customer needs arise (Amabile, 1988; Wong \& Ladkin, 2008). Empirical research also suggests that extrinsic motivators such as opportunities for development, good wages, and job security are positively related to job creativity among hotel employees (Wong \& Ladkin, 2008). Hence, the following hypotheses are proposed. $H 5_{0}$ : Intrinsic motivation is not related to employee innovative behavior. $H 5_{a}$ : Intrinsic motivation is positively related to employee innovative behavior. $H 6_{0}$ : Extrinsic motivation is not related to employee innovative behavior. $H 6_{a}$ : Extrinsic motivation is positively related to employee innovative behavior. $<<<$ Insert Figure $1>>>$ 


\section{RESEARCH METHODS}

Survey Instrument Development

We tested the proposed research hypotheses using structural equation modeling of data collected through a mixed-mode survey using a questionnaire. The questionnaire included measures of customer interactivity $(\mathrm{CI})$, positive affect (PA), intrinsic motivation (IM), extrinsic motivation (EM), and employee innovative behavior (EIB), as well as questions about respondents' social demographics (e.g., gender, age, education, position, and length in industry).

Customer interactivity (CI). The measurement scale for CI was developed from Bonner's (2010) 10-item scale, which we adapted to suit the study context. One original item, which focused on corporate customers ("Customers often participated in working meetings with project members"), was adapted to reflect an individual customer focus: "Customers had many opportunities to evaluate services and products at the hotel."

Positive affect (PA). A three-item PA scale from Pugh (2001), George and Brief (1992), and Barnes et al. (2015) was used. An example item is "When I remember delightful service encounters, I feel enthusiastic about my work."

Employee motivations. Intrinsic motivation for work (IM) was measured by four items from Low, Cravens, Grant, and Moncrief (2001). An example item is "I feel a great sense of personal satisfaction when I do my job well.” Extrinsic motivation for work (EM) was assessed with a six-item scale developed by Amabile et al. (1994) and Sung and Choi (2009). An example item is "I am strongly motivated by the recognition I can earn from other 
people."

Employee innovative behavior (EIB). We measured EIB with a six-item scale following Scott and Bruce (1994) and Hu, Horng, and Sun (2009). A sample item was "At work, I come up with innovative and creative notions."

All items in the questionnaire were measured on a 7-point Likert-type scale $(1=$ "strongly disagree" to 7 = "strongly agree"). The questionnaire was developed in English, and translated into Chinese by a bilingual hospitality management professor working in a Chinese university. To ensure equivalence of meaning (Brislin, 1980), the translated questionnaire was then verified and cross-checked by two other bilingual tourism and hospitality scholars, who suggested minor revisions to the questionnaire. Following Chang, Van Witteloostuijn, and Eden (2010), we randomly ordered the questions and mixed items from different constructs to reduce potential common method bias.

A pilot study of a sample of 196 employees of a four-star hotel in a northern city in China resulted in minor adjustments to the questionnaire to improve clarity. For instance, participants felt that several items contained awkward expressions that are inconsistent with common expressions in Mandarin, and these were adjusted for greater readability. Results of an exploratory factor analysis (EFA) for the main constructs indicated a two-factor structure for customer interactivity, with the second factor containing only one item. After deletion of the item, the factor analysis on the remaining nine items suggested one factor explaining $62.42 \%$ of the total variance with a Cronbach's alpha of .92 (Hair, Black, Babin, Anderson, \& Tatham, 2006). This one-factor structure of customer interactivity was later confirmed in the main study (Cronbach's alpha $=0.92$, total variance explained $=59.97 \%)$. 
A mixed-mode survey was carried out in China from January to April in 2018 using a paper-based survey supplemented by an online survey. Methodologically, mixed-mode designs offer an opportunity to compensate for weaknesses of a single mode and reduce coverage bias and non-response bias (de Leeuw, 2005). Research has confirmed that the quality and reliability of data collected by paper-and-pencil and Internet-based methods are generally equivalent (Denscombe, 2006). Practically, a mixed-mode design was deemed necessary because some hotels agreed to on-site data collection whereas others stated that an online survey was the only acceptable option for their hotels. Therefore, both distribution methods were used to better ensure the size and representativeness of the sample.

Hotel ratings signify quality of service, customer relationship, and value creation opportunities (Park \& Allen, 2013). Therefore, four- and five-star hotels would offer a work environment more conducive to employee innovative behavior (Tajeddini, 2011). We accessed potential participating hotels through the research team's personal connections and their referrals. In total, six four-star and eight five-star hotels agreed to participate in the study. These hotels are located in 11 cities (Beijing, Guangzhou, Hangzhou, Ningbo, Chengdu, Jinan, Qingdao, Rizhao, Zibo, Zhengzhou, and Baishan) in seven provinces (Beijing, Guangdong, Zhejiang, Sichuan, Shandong, Henan, and Jilin), and represent 13 chain and independent brands. These cities have vigorous economic, cultural, and internalization programs as well as vibrant tourism and hospitality markets. Employees of the participating hotels come from diverse regions of China. The sampling framework was limited to full-time employees in the hotels' front office and housekeeping, food and beverage, marketing, and 
recreation departments. These employees included front-line employees, supervisors, and managers who routinely interact with customers, who were either traveling personally or as representatives of corporate customers.

In seven hotels and with permission and full support from senior executives of the hotels, paper-based questionnaires were distributed to employees face-to-face on site during work hours. To avoid social desirability issues, the researchers excused themselves from the data collection sites while respondents completed the questionnaires, and returned later to collect the completed questionnaires in sealed envelopes. Of the 800 distributed paper questionnaires, 763 were returned and 683 were usable for analysis.

For the online survey, Sojump (or Wen Juan Xing in Chinese), a reputable professional survey platform in China, was chosen to host the questionnaire. Seven of the 14 hotels preferred participation via the web-based survey. An invitation email with the questionnaire link embedded was sent to senior executives of these hotels, who then forwarded the email to potential participants. Of the 280 invitations distributed, 157 returned as usable completions.

In total, 840 valid questionnaires were collected via online and face-to-face surveys. As data were collected using two different modes, the two sets of data were compared to check whether a mode effect existed (Denscombe, 2006). Chi-square test results indicated no statistically significant difference $(p>.05)$ in the distribution of 26 quantitative items, with the exception of one item in the EIB scale. Thus, data collected by the two distribution modes were generally equivalent and could be combined for data analysis.

Normality tests for the variables returned maximum absolute values of skewness and 
kurtosis of all variables of 1.97 and 6.15, respectively (most values were lower than 1 ), which are within acceptable limits (skewness $<2$, kurtosis $<7$ ) (Curran, West, \& Finch, 1996). The chi-square test result $(p<.001)$ suggests that the sample does not satisfy the multivariate normality assumption. However, our sample size was larger than 600, meeting the sample size requirement for a sample with multivariate non-normal distribution (Gao, Mokhtarian, \& Johnston, 2008). We used the Mahalanobis squared distance $\left(p_{1}<.001, p_{2}<.001\right)$ to identify multivariate outliers. After the elimination of 10 outliers, the final sample for model testing included 830 respondents.

Because all data were collected through employees' self-reports, Harman's one-factor test was conducted to check for common method bias (Podsakoff \& Organ, 1986). The result did not reveal a single-factor structure and the first factor accounted for $39.87 \%$ of the variance explained, which is less than the critical value of $40 \%$ (Liu, Luo, \& Shi, 2002). Hence, common method bias is not a concern in our data.

\section{RESULTS}

\section{Sample Characteristics}

As shown in Table 1, more than half of the respondents were female $(62.0 \%)$, reflecting the reality that the majority of front-line employees in Chinese hotels are female (Chen, Chang, \& Wang, 2018; Li \& Hsu, 2016a). Over two-thirds were aged 35 or below. Most respondents had attained a college diploma or below, and $7.9 \%$ had a bachelor's degree or higher. Three-quarters of respondents were common staff with the rest working in a supervisory $(19.0 \%)$ or a managerial role $(5.8 \%)$, and $27.6 \%$ of the respondents had worked 
for less than one year in a hotel.

$$
<<<\text { Insert Table } 1>>>
$$

\section{Measurement Model Results}

We conducted a CFA on the overall sample data $(n=830)$ using AMOS 17.0 with all constructs modeled simultaneously as correlated factors with the maximum likelihood estimation method. Two items (one from the IM scale and the other from the EM scale) were eliminated owing to a factor loading value lower than 0.5 (Hair et al., 2006). Overall, the results indicated acceptable psychometric properties (Table 2). Each construct exhibited a composite reliability (CR) exceeding the recommended threshold values of .7, suggesting reliability of the measures. The results of the analysis indicated a good fit (Byrne, 2001), with $\chi^{2}=1000.35, \mathrm{df}=277, p<.01 ; \chi 2 / \mathrm{df}=3.61 ; \mathrm{GFI}=.91, \mathrm{CFI}=.95, \mathrm{NFI}=.93, \mathrm{TLI}=.94$, $\mathrm{RMSEA}=.06$, and SRMR $=.05$.

Convergent validity was evidenced by statistically significant item factor loadings (Anderson \& Gerbing, 1988). As indicated in Table 2, the standardized factor loadings of measurement items were significant, ranging from .63 to .93 or moderate to strong $(>.5)$, with $t$ values greater than the recommended threshold values of 1.96 (Netemeyer, Bearden, \& Sharma, 2003), suggesting that all items were significant indicators of their respective constructs $(p<.01)$ and providing support for convergent validity. In addition, the average variance extracted (AVE) of all constructs ranged from .52 to .75 (see Table 2), which was greater than the .50 threshold (Bagozzi \& Yi, 1988). Thus, convergent validity for the measurement-scale items was achieved. Discriminant validity was evaluated by comparing the square root of AVE values and the correlation coefficient between constructs (Fornell \& 
Larcker, 1981). As reported in Table 3, each construct's square root of AVE was higher than construct correlations, confirming discriminant validity.

$<<<$ Insert Tables 2 and $3>>>$

\section{Structural Model Results}

A structural equation model was estimated to empirically validate the conceptual model and included employees' gender, age, education level, position and length of experience in the industry as control variables, as these factors may influence employee innovative behavior (Scott \& Bruce, 1994). The estimated structural model showed satisfactory model fit $\left(\chi^{2}=1544.32, \mathrm{df}=408, \chi 2 / \mathrm{df}=3.79, p<.01, \mathrm{GFI}=.89, \mathrm{CFI}=.92, \mathrm{NFI}\right.$ $=.90, \mathrm{TLI}=.91, \mathrm{RMSEA}=.06$, and SRMR $=.05)$. Table 4 displays the estimates for the overall structural model and the hypothesized paths. The effects of customer interactivity on employee innovative behavior $(\beta=.27, p<.001)$ and positive affect $(\beta=.20, p<.001)$ were significant. Thus, Hypotheses $1_{0}$ and $2_{0}$ were rejected and Hypotheses $1_{\mathrm{a}}$ and $2_{\mathrm{a}}$ were accepted. Customer interactivity was positively related to intrinsic motivation $(\beta=.17, p$ $<.001)$ and extrinsic motivation $(\beta=.34, p<.001)$, rejecting Hypothesis $3_{0}$ and accepting alternative Hypothesis $3_{\mathrm{a}}$.

Results also revealed that positive affect was positively related to intrinsic motivation $(\beta=.38, p<.001)$ and extrinsic motivation $(\beta=.41, p<.001)$, rejecting null Hypothesis $4_{0}$ and accepting alternative Hypothesis 4 a. In addition, as intrinsic motivation $(\beta=.22, p$ $<.001)$ and extrinsic motivation $(\beta=.47, p<.001)$ were positively and significantly related to employee innovative behavior, Hypothesis $5_{0}$ and Hypothesis $6_{0}$ were thus rejected and alternative Hypothesis $5 \mathrm{a}$ and Hypothesis 6 a were accepted. 
$<<<$ Insert Table 4 here $>>>$

We further assessed the indirect effects of customer interactivity through positive affect, intrinsic motivation, and extrinsic motivation by performing bias-corrected percentile bootstrapping at a 95\% confidence interval with 1,000 bootstrap samples (Taylor, MacKinnon, \& Tein, 2008). The confidence interval of the lower and upper bounds was used to determine whether the indirect effects were significant (Hayes, 2013). As shown in Table 4, test results confirmed the existence of a positive and significant indirect effect of interactivity through positive affect on intrinsic motivation $(\beta=.13, \mathrm{p}<.001,95 \% \mathrm{BCa} \mathrm{CI}$ $[.08, .18])$ and extrinsic motivation $(\beta=.10, \mathrm{p}<.001,95 \%$ BCa CI $[.06, .15])$. Similarly, positive and significant indirect effects through positive affect, intrinsic motivation, and extrinsic motivation were found between customer interactivity and employee innovative behavior $(\beta=.30, \mathrm{p}<.001,95 \%$ BCa CI $[.24, .37])$.

\section{DISCUSSION AND IMPLICATIONS}

Drawing on the S-O-R framework, this study conceptualized an employee innovative behavior model that investigates the role of customer interactivity, positive affect, and intrinsic and extrinsic motivations in enhancing employee innovative behavior in hotels. The model was tested on a sample of 830 hotel employees of four- and five-star hotels in China and all hypotheses were supported. The results of the study support previous arguments that link customer interactivity to employee psychology (Barnes et al., 2015; Hartline \& Ferrell, 1996), demonstrating that effective employee-customer interaction and exchange of ideas can affect hotel employees' motivation and innovation not only directly, but also indirectly 
through influencing employees' emotional states.

\section{Theoretical Implications}

The results of this study contribute to the literature by exploring the mechanisms underlying the relationship between customer-employee interactivity (as an important manifestation of customer engagement) and employee innovative behavior. First, by focusing on customer-employee interactivity, this study extends the investigation of customer engagement into the offline service delivery and innovation domain, and addresses the call to strengthen research on the antecedents and outcomes of customer engagement (So, King, Sparks, \& Wang, 2016). The study conceptualizes customer engagement's interactive dimension as a stimulus to elicit hotel employees' innovative behaviors at an individual level, thereby differentiating our study from previous studies, which view customer engagement as psychological engagement or behavioral participation toward a brand or a firm.

Second, our study responds to the call for expansion of the scope of the S-O-R model in hospitality settings (Ahn \& Seo, 2018). Prior studies have adopted the S-O-R model to examine from a marketing perspective how the customer's emotions and behaviors are influenced by a hotel's environmental attributes, services, or staff behavior (e.g., Choi \& Kandampully, 2019; Jani \& Han, 2015). In contrast, our study expanded the S-O-R model by considering the complexity within the "O" element and simultaneously testing the effects of multiple organismic responses. The study revealed that customer-employee interactivity can induce hotel employees' organismic responses of positive affect and motivations, which in turn lead to employees' innovative behaviors. Our findings highlight the dynamic nature of the organismic component of the S-O-R model and suggest that multiple factors are at play to 
collectively lead to a behavioral response. Our conceptualization of customer interactivity as a stimulus and incorporation of multiple organismic responses in the model are novel. Furthermore, the study extends the application of the S-O-R framework to an organizational behavior context in hotels.

Third, with respect to interactivity at the individual employee and customer levels, the study also differentiates itself from the predominant focus of previous studies on customerfirm interactivity (Foss et al., 2011) and customer-technology interactivity (e.g., Barreda, Bilgihan, Nusair, \& Okumus, 2016). As the study's results reveal, direct interactions with customers during service delivery can, directly and indirectly, influence employees' innovative behaviors.

Another theoretical contribution relates to the study's consideration of the psychological mechanisms underlying employees' innovative behaviors and positive affect in the workplace, in contrast to previous conceptualizations that interactivity exercises its influence by engaging employees in a cognitive process (Liu \& Shrum, 2002). As one of the few attempts to clarify the role of employees' emotional state in influencing their performance, this study reveals how customer interactivity influences employee innovative behavior through the psychological mechanisms of positive affect and intrinsic and extrinsic motivations. This finding suggests that researchers should consider emotional constructs, such as the emotional intelligence of employees when studying organizational and employee performance.

\section{Practical Implications}

This study also has several practical implications for enhancing employee-based 
innovativeness. First, the findings highlight the significance of customer interactivity to innovations in hotels. To maximize opportunities for two-way customer-employee communication on a comprehensive range of service attributes, hotels should establish a facilitating mechanism for customer-employee interactivity throughout the service process (i.e., before, during, and after customer stay). Hotels should formulate internal policies and operational procedures to ensure that employees initiate two-way communication with customers before their arrival at the hotel. Such actions can include direct contact with customers to inform available services and matters needing attention (such as customer service contact details and weather forecasts), soliciting information from customers about their travel arrangements, and confirmation of special requests for elderlies and children. Hotels should also identify critical service touch points for customer-employee interactivity (e.g., check-in, end of a meal, and check-out) and establish and communicate service protocols to employees to ensure regular two-way interaction throughout customers' duration of stay. After check-out, hotels should maintain interaction with customers via social mediabased brand communities and actions such as customer satisfaction survey, solicitation of customer feedback, holiday greetings, and birthday wishes. Employees may be encouraged to keep in touch with customers if positive rapport has been established between the two parties. An effective facilitating mechanism for customer-employee interactivity should ensure timely handling of customer feedback and include continuous skill development for employees so they can effectively deliver interactive and personalized services to customers. For instance, hotels should reward employees who regularly solicit and respond to customer feedback, and should provide effective channels for employees to report customer feedback 
in a timely manner. In addition, as employees inevitably encounter problems and customer complaints during service delivery, hotels should investigate ways to encourage and empower on-site joint problem solving by employees and customers. This collaboration may be achieved by (1) incorporating joint problem solving into performance evaluation, (2) improving employees' problem-solving, communication, and service skills through training and development programs, (3) instilling a sense of duty in employees through better internal engagement strategies, and (4) adjusting/clarifying individuals' responsibilities. Hotels should incentivize on-site problem solving through both financial and non-financial rewards.

Second, the significant effect of motivations identified in this study points to the need for hotels to establish an environment that satisfies both intrinsic and extrinsic motivations of their employees. With a higher standardized regression weight, extrinsic motivations proved to be a stronger predictor of customer innovative behavior than intrinsic motivations. This result may be related to the relatively low pay and low social status of hotel staff (McGinley, Hanks, \& Line, 2017) and may also indicate that the hotel job is less inherently satisfying as its incentives are directly related to performance or results, making extrinsic motivation the main driving force for employees to do the work (Kuvaas et al., 2017). Indeed, contrary to public perceptions in the 1990s that hotels in China offered a good work environment and higher than average salaries, hotels are no longer able to provide good packages that meet employee expectations (Zhang \& Wu, 2004). The stronger influence of extrinsic motivation found in this study also aligns with evidence obtained outside the hospitality industry that financial incentives relate positively to performance and extrinsic motivation asserts a stronger influence than intrinsic motivation (Jenkins, Mitra, Gupta, \& Shaw, 1998). 
Extrinsic motivations are more goal-driven and can be encouraged by a wellestablished benefit and reward system (Lin, 2007), such as improvements in salary level, vacation discounts, and free employee meals (McGinley et al., 2017). Therefore, as mentioned earlier, the hotel incentive system can incorporate measures and rewards related to customer interaction and engagement. Further, hotels should intrinsically motivate employees, possibly by providing organizational support. For instance, adopting developmental rather than evaluative evaluation systems to provide feedback on specific innovative behaviors can alleviate the fear and anxiety of uncertainty caused by innovation. Hotels must create an atmosphere and culture of emphasizing customer interactivity, encouraging employee feedback, and empowering employee innovative behaviors.

Third, positive affect plays an indirect role between customer interactivity and employee innovative behavior. It is thus also worthwhile for hotels to invest in practices that facilitate the elicitation of positive affect of employees, such as providing more assistance for employees. In particular, supervisor or co-worker support is important to improving employees' satisfaction and positive emotion (Susskind, Kacmar, \& Borchgrevink, 2018). In addition, the human resource department can consider recruiting employees who possess positive affectivity and extraversion traits, which may help build a more positive and innovative workforce at the hotel.

\section{Limitations and Research Directions}

Our study has several limitations. First, the study's focus on four- and five-star hotels limits the generalizability of the findings. Further investigation is required to validate our model in hotels of lower star ratings, especially given that the expected level of customer 
relationship and value creation are lower in these hotels (Park \& Allen, 2013). Second, while our study focuses on positive affect, in reality, both positive and negative emotions may arise from customer-employee interactivity. Evidence outside the tourism and hospitality literature reveals no facilitating role of negative affect on employee innovative behavior (Choi, Sung, Lee, \& Cho, 2011). Future research is required for insights into the role of negative affect in shaping employee innovation and performance in hotels. Third, this study viewed interactivity as a social stimulus in a service environment without investigating the antecedents of interactivity, such as organizational process as well as compensation and benefits scheme. Future research shall explore the causes of and barriers to interactivity and how these factors interact with employee motivations to influence their innovative behaviors. In addition, our data did not support the three-dimensional structure of interactivity, which raises a need for further investigation into the nature of this construct in a hospitality context and for a service-specific measurement scale for interactivity.

\section{Concluding Summary}

This research contributes to the tourism and hospitality literature by conceptualizing and testing the roles of customer interactivity, positive affect, and employee motivations in enhancing employee innovative behavior in hotels. Based on structural equation modeling of data collected from 830 hotel employees in China using a mixed-mode quantitative survey, the study demonstrates the theoretical and practical importance of focusing on employeecustomer interactions at hotels as such interactions can affect employees' motivation and innovation not only directly, but also indirectly through influencing employees' emotional 
states.

\section{REFERENCES}

Ahn, J. A., \& Seo, S. (2018). Consumer responses to interactive restaurant self-service technology (IRSST): The role of gadget-loving propensity. International Journal of Hospitality Management, 74, 109-121.

Alvarez-Milán, A., Felix, R., Rauschnabel, P. A., \& Hinsch, C. (2018). Strategic customer engagement marketing: A decision making framework. Journal of Business Research, $92,61-70$.

Amabile, T. M. (1988). A model of creativity and innovation in organizations. Research in Organizational Behavior, 10(1), 123-167.

Amabile, T. M. (1993). Motivational synergy: Toward new conceptualizations of intrinsic and extrinsic motivation in the workplace. Human Resource Management Review, 3(3), $185-201$.

Amabile, T. M., Hill, K. G., Hennessey, B. A., \& Tighe, E. M. (1994). The work preference inventory: Assessing intrinsic and extrinsic motivational orientations. Journal of Personality and Social Psychology, 66(5), 950-967.

Anderson, J. C., \& Gerbing, D. W. (1988). Structural equation modeling in practice: A review and recommended Two-Step approach. Psychological Bulletin, 103(3), 411-423.

Aspinwall, L. G. (1998). Rethinking the role of positive affect in self-regulation. Motivation and Emotion, 22(1), 1-32.

Attiq, S. (2015). Attention to social comparison information and compulsive buying behavior: An S-O-R analysis. Journal of Behavioural Sciences, 25(1), 40-58.

Bagozzi, R. P., \& Yi, Y. (1988). On the evaluation of structural equation models. Journal of 
the Academy of Marketing Science, 16(1), 74-94.

Bani-Melhem, S., Zeffane, R., \& Albaity, M. (2018). Determinants of employees' innovative behavior. International Journal of Contemporary Hospitality Management, 30(3), 1601-1620.

Barnes, D. C., Ponder, N., \& Hopkins, C. D. (2015). The impact of perceived customer delight on the frontline employee. Journal of Business Research, 68(2), 433-441.

Barreda, A. A., Bilgihan, A., Nusair, K., \& Okumus, F. (2016). Online branding:

Development of hotel branding through interactivity theory. Tourism Management, 57, 180-192.

Bonner, J. M. (2005). The influence of formal controls on customer interactivity in new product development. Industrial Marketing Management, 34(1), 63-69.

Bonner, J. M. (2010). Customer interactivity and new product performance: Moderating effects of product newness and product embeddedness. Industrial Marketing Management, 39(3), 485-492.

Brislin, R. W. (1980). Translation and content analysis of oral and written material. In H.C. Triandis \& J.W. Berry (Eds.), Handbook of Cross-Cultural Psychology (pp. 389-444). Boston, MA: Allyn \& Bacon.

Brodie, R.J., Hollebeek, L.D., Jurić, B., \& Ilić, , A. (2011). Customer engagement: Conceptual domain, fundamental propositions, and implications for research. Journal of Service Research, 14(3), 252-271.

Buxbaum, O. (2016). Key insights into basic mechanisms of mental activity. Switzerland: Springer International Publishing.

Byrne, B. M. (2001). Structural equation modeling with AMOS, EQS, and LISREL:

Comparative approaches to testing for the factorial validity of a measuring instrument. International Journal of Testing, 1(1), 55-86. 
Cadwallader, S., Jarvis, C. B., Bitner, M. J., \& Ostrom, A. L. (2010). Frontline employee motivation to participate in service innovation implementation. Journal of the Academy of Marketing Science, 38(2), 219-239.

Chang, S. J., Van Witteloostuijn, A., \& Eden, L. (2010). From the editors: Common method variance in international business research. Journal of International Business Studies, 41(2), 178-184.

Chen, K. Y., Chang, C. W., \& Wang, C. H. (2018). Frontline employees' passion and emotional exhaustion: The mediating role of emotional labor strategies. International Journal of Hospitality Management, 76,163-172.

Chen, W. J. (2011). Innovation in hotel services: Culture and personality. International Journal of Hospitality Management, 30(1), 64-72.

Chiang, C. F., \& Jang, S. S. (2008). An expectancy theory model for hotel employee motivation. International Journal of Hospitality Management, 27(2), 313-322.

Choi, H., \& Kandampully, J. (2019). The effect of atmosphere on customer engagement in upscale hotels: An application of S-O-R paradigm. International Journal of Hospitality Management, 77, 40-50.

Choi, J. N., Sung, S.Y., Lee, K., \& Cho, D. (2011). Balancing cognition and emotion: Innovation implementation as a function of cognitive appraisal and emotional reactions toward innovation. Journal of Organizational Behavior, 32(1), 107-124.

Coelho, F., Augusto, M., \& Lages, L. F. (2011). Contextual factors and the creativity of frontline employees: The mediating effects of role stress and intrinsic motivation. Journal of Retailing, 87(1), 31-45.

Cui, A. S., \& Wu, F. (2016). Utilizing customer knowledge in innovation: Antecedents and impact of customer involvement on new product performance. Journal of the Academy of Marketing Science, 44(4), 516-538. 
Curran, P. J., West, S. G., \& Finch, J. F. (1996). The robustness of test statistics to nonnormality and specification error in confirmatory factor analysis. Psychological Methods, 1(1), 16.

Deci, E. L. (1975). Intrinsic motivation. New York, NY: Plenum Press.

Deci, E. L., Connell, J. P., \& Ryan, R. M. (1989). Self-determination in a work organization. Journal of Applied Psychology, 74(4), 580-590.

Deci, E. L., \& Ryan, R. M. (1985). Intrinsic motivation and self-determination in human behavior. New York, NY: Plenum Press.

Deci, E. L., \& Ryan, R. M. (2000). The "what" and "why" of goal pursuits: Human needs and the self-determination of behavior. Psychological Inquiry, 11(4), 227-268.

de Leeuw, E. D. (2005). To mix or not to mix data collection modes in surveys. Journal of Official Statistics, 21(1), 233-255.

Denscombe, M. (2006). Web-based questionnaires and the mode effect: An evaluation based on completion rates and data contents of near-identical questionnaires delivered in different modes. Social Science Computer Review, 24(2), 246-254.

Fornell, C., \& Larcker, D. F. (1981). Evaluating structural equation models with unobservable variables and measurement error. Journal of Marketing Research, 18(1), 39-50.

Fortin, D. R., \& Dholakia, R. R. (2005). Interactivity and vividness effects on social presence and involvement with a web-based advertisement. Journal of Business Research, $58(3), 387-396$.

Foss, N. J., Laursen, K., \& Pedersen, T. (2011). Linking customer interaction and innovation: The mediating role of new organizational practices. Organization Science, 22(4), 980999.

Fowler, K., \& Bridges, E. (2012). Service environment, provider mood, and providercustomer interaction. Journal of Service Theory \& Practice, 22(2), 165-183. 
Gao, S., Mokhtarian, P., \& Johnston, R. (2008). Nonnormality of data in structural equation models. Journal of the Transportation Research Board, 2082, 116-124.

George, J., \& Brief, A. (1992). Feeling good-doing good: A conceptual analysis of the mood at work-organizational spontaneity. Psychological Bulletin, 112(2), 310-329.

Gruner, K. E., \& Homburg, C. (2000). Does customer interaction enhance new product success? Journal of Business Research, 49(1), 1-14.

Gu, H., Duverger, P., \& Yu, L. (2017). Can innovative behavior be led by management? A study from the lodging business. Tourism Management, 63, 144-157.

Gumusluoglu, L., \& Ilsev, A. (2009). Transformational leadership, creativity, and organizational innovation. Journal of Business Research, 62(4), 461-473.

Hair, J. F., Black, W. C., Babin, B. J., Anderson, R. E., \& Tatham, R. L. (2006). Multivariate data analysis (6th ed.). Upper Saddle River, NJ: Pearson Prentice Hall.

Hartline, M. D., \& Ferrell, O. C. (1996). The management of customer-contact service employees: An empirical investigation. Journal of Marketing, 60(4), 52-70.

Hayes, A. F. (2013). Introduction to mediation, moderation, and conditional process analysis: A regression-based approach. New York, NY: The Guilford Press.

Hew, J. J., Leong, L. Y., Tan, G. W. H., Lee, V. H., \& Ooi, K. B. (2018). Mobile social tourism shopping: A dual-stage analysis of a multi-mediation model. Tourism Management, 66, 121-139.

Hon, A. H. (2012). Shaping environments conductive to creativity: The role of intrinsic motivation. Cornell Hospitality Quarterly, 53(1), 53-64.

Hu, M. L. M., Horng, J. S., \& Sun, Y. H. C. (2009). Hospitality teams: Knowledge sharing and service innovation performance. Tourism Management, 30(1), 41-50.

Isen, A. M., \& Reeve, J. (2005). The influence of positive affect on intrinsic and extrinsic motivation: Facilitating enjoyment of play, responsible work behavior, and self- 
control. Motivation and Emotion, 29(4), 295-323.

Jang, S. S., \& Namkung, Y. (2009). Perceived quality, emotions, and behavioral intentions: Application of an extended Mehrabian-Russell model to restaurants. Journal of Business Research, 62(4), 451-460.

Jani, D., \& Han, H. (2015). Influence of environmental stimuli on hotel customer emotional loyalty response: Testing the moderating effect of the big five personality factors. International Journal of Hospitality Management, 44, 48-57.

Janssen, O. (2001). Fairness perceptions as a moderator in the curvilinear relationships between job demands, and job performance and job satisfaction. Academy of Management Journal, 44(5), 1039-1050.

Jenkins, G. D., Mitra, A., Gupta, N., \& Shaw, J. D. (1998). Are financial incentives related to performance? A meta-analytic review of empirical research. Journal of Applied Psychology, 83(5), 777-787.

Kahn, B. E., \& Isen, A. M. (1993). The influence of positive affect on variety seeking among safe, enjoyable products. Journal of Consumer Research, 20(2), 257-270.

Kelley, H. H., \& Thibaut, J. W. (1978). Interpersonal relations: A theory of interdependence. New York, NY: Wiley.

Kiffin-Petersen, S., Murphy, S. A., \& Soutar, G. (2012). The problem-solving service worker: Appraisal mechanisms and positive affective experiences during customer interactions. Human Relations, 65(9), 1179-1206.

Kim, K., \& Baker, M. A. (2019). How the employee looks and looks at you: Building customer- employee rapport. Journal of Hospitality \& Tourism Research, 43(1), 20Developing a scale40.

Kumar, V., Aksoy, L., Donkers, B., Venkatesan, R., Wiesel, T., \& Tillmans, S. (2010). Undervalued or overvalued customers: Capturing total customer engagement value. 
Journal of Service Research, 13(3), 297-310.

Kuvaas, B., Buch, R., Weibel, A., Dysvik, A., \& Nerstad, C. G. (2017). Do intrinsic and extrinsic motivation relate differently to employee outcomes? Journal of Economic Psychology, 61, 244-258.

Lai, J., Hon, A. H. Y., \& Lui, S. S. (2014). Does standardized service fit all? Novel service encounter in frontline employee-customer interface. International Journal of Contemporary Hospitality Management, 26(8), 1341-1363.

Lee, J. J., \& Ok, C. (2012). Reducing burnout and enhancing job satisfaction: Critical role of hotel employees' emotional intelligence and emotional labor. International Journal of Hospitality Management, 31(4), 1101-1112.

Li, M., \& Hsu, C. H. (2016a). A review of employee innovative behavior in services. International Journal of Contemporary Hospitality Management, 28(12), 2820-2841.

Li, M., \& Hsu, C. H. (2016b). Linking customer-employee exchange and employee innovative behavior. International Journal of Hospitality Management, 56, 87-97.

Li, M., \& Hsu, C. H. C. (2018). Customer participation in services and employee innovative behavior: The mediating role of interpersonal trust. International Journal of Contemporary Hospitality Management, 30(4), 2112-2131.

Lin, H. F. (2007). Effects of extrinsic and intrinsic motivation on employee knowledge sharing intentions. Journal of Information Science, 33(2), 135-149.

Liu, S. S., Luo, X., \& Shi, Y. Z. (2002). Integrating customer orientation, corporate entrepreneurship, and learning orientation in organizations-in-transition: An empirical study. International Journal of Research in Marketing, 19(4), 367-382.

Liu, Y. (2003). Developing a scale to measure the interactivity of websites. Journal of Advertising Research, 43(2), 207-216.

Liu, Y., \& Shrum, L. J. (2002). What is interactivity and is it always such a good thing? 
Implications of definition, person, and situation for the influence of interactivity on advertising effectiveness. Journal of Advertising, 31(4), 53-64.

Low, G. S., Cravens, D. W., Grant, K., \& Moncrief, W. C. (2001). Antecedents and consequences of salesperson burnout. European Journal of Marketing, 35(5/6), 587611.

Ma, E., \& Qu, H. (2011). Social exchanges as motivators of hotel employees' organizational citizenship behavior: The proposition and application of a new three-dimensional framework. International Journal of Hospitality Management, 30(3), 680-688.

McGinley, S. P., Hanks, L., \& Line, N. D. (2017). Constraints to attracting new hotel workers: A study on industrial recruitment. International Journal of Hospitality Management, 60, 114-122.

Mehrabian, A., \& Russell, J.A. (1974). An approach to environmental psychology. Cambridge, MA: MIT Press.

Mohr, J., \& Nevin, J. R. (1990). Communication strategies in marketing channels: A theoretical perspective. Journal of Marketing, 54(4), 36-51.

Namkung, Y., Jang, S. S., \& Choi, S. K. (2011). Customer complaints in restaurants: Do they differ by service stages and loyalty levels? International Journal of Hospitality Management, 30(3), 495-502.

Netemeyer, R. G., Bearden, W. O., \& Sharma, S. (2003). Scaling procedures: Issues and applications. Thousand Oaks, CA: Sage Publications.

Nieves, J., Quintana, A., \& Osorio, J. (2014). Knowledge-based resources and innovation in the hotel industry. International Journal of Hospitality Management, 38, 65-73.

Ohly, S., \& Fritz, C. (2010). Work characteristics, challenge appraisal, creativity, and proactive behavior: A multi-level study. Journal of Organizational Behavior, 31(4), 
$543-565$.

Park, S. Y., \& Allen, J. P. (2013). Responding to online reviews: Problem solving and engagement in hotels. Cornell Hospitality Quarterly, 54(1), 64-73.

Pieterse, A. N., Van Knippenberg, D., Schippers, M., \& Stam, D. (2010). Transformational and transactional leadership and innovative behavior: The moderating role of psychological empowerment. Journal of Organizational Behavior, 31(4), 609-623.

Pugh, S. D. (2001). Service with a smile: Emotional contagion in the service encounter. Academy of Management Journal, 44(5), 1018-1027.

Putra, E. D., Cho, S., \& Liu, J. (2017). Extrinsic and intrinsic motivation on work engagement in the hospitality industry: Test of motivation crowding theory. Tourism and Hospitality Research, 17(2), 228-241.

Podsakoff, P. M., \& Organ, D. W. (1986). Self-reports in organizational research: Problems and prospects. Journal of Management, 12(4), 531-544.

Ryu, K., \& Lee, J. S. (2017). Examination of restaurant quality, relationship benefits, and customer reciprocity from the perspective of relationship marketing investments. Journal of Hospitality \& Tourism Research, 41(1), 66-92.

Sahu, A., \& Srivastava, K. B. L. (2017). Antecedents and consequences of positive emotions in the workplace. International Journal of Work Organization \& Emotion, 8(2), 99217.

Schaarschmidt, M., Walsh, G., \& Evanschitzky, H. (2018). Customer interaction and innovation in hybrid offerings: Investigating moderation and mediation effects. Journal of Service Research, 21(1), 119-134.

Schuhmacher, M. C., \& Kuester, S. (2012). Identification of lead user characteristics driving the quality of service innovation ideas. Creativity \& Innovation Management, 21(4), 427-442. 
Scott, S. G., \& Bruce, R. A. (1994). Determinants of innovative behavior: A path model of individual innovation in the workplace. Academy of Management Journal, 37(3), 580607.

Sheehan, J. (2006). Understanding service sector innovation. Communications of the ACM, 49(7), 42-47.

Sheng, H., \& Joginapelly, T. (2012). Effects of web atmospheric cues on users' emotional responses in e-commerce. AIS Transactions on Human-Computer Interaction, 4(1), 124.

Slåtten, T., \& Mehmetoglu, M. (2011). Antecedents and effects of engaged frontline employees: A study from the hospitality industry. Journal of Service Theory \& Practice, 21(1), 88-107.

So, K. K. F., King, C., \& Sparks, B. (2014). Customer engagement with tourism brands: Scale development and validation. Journal of Hospitality \& Tourism Research, 38(3), 304-329.

So, K. K. F., King, C., Sparks, B. A., \& Wang, Y. (2016). The role of customer engagement in building consumer loyalty to tourism brands. Journal of Travel Research, 55(1), 6478.

Solomon, M. R., Surprenant, C., Czepiel, J.A., \& Gutman, E. G. (1985). A role theory perspective on dyadic interactions: The service encounter. Journal of Marketing, 49(1), 99-111.

Sung, S. Y., \& Choi, J. N. (2009). Do Big Five personality factors affect individual creativity? The moderating role of extrinsic motivation. Social Behavior and Personality, 37(7), 941-956.

Susskind, A. M., Kacmar, K. M., \& Borchgrevink, C. P. (2018). Guest-server exchange model and performance: The connection between service climate and unit-level sales 
in multiunit restaurants. Journal of Hospitality \& Tourism Research, 42(1), 122-141.

Tajeddini, K. (2011). Customer orientation, learning orientation, and new service development: An empirical investigation of the Swiss hotel industry. Journal of Hospitality \& Tourism Research, 35(4), 437-468.

Taylor, A. B., MacKinnon, D. P., \& Tein, J. Y. (2008). Tests of the three-path mediated effect. Organizational Research Methods, 11(2), 241-269.

Teng, C. C., \& Barrows, C. W. (2009). Service orientation: antecedents, outcomes, and implications for hospitality research and practice. The Service Industries Journal, 29 (10), 1413-1435.

Vroom, V. H. (1964). Work and motivation. New York, NY: Wiley.

Watson, D., Clark, L. A., \& Tellegen, A. (1988). Development and validation of brief measures of positive and negative affect: The PANAS scales. Journal of Personality and Social Psychology, 54(6), 1063-1070.

Wong, S. C. K., \& Ladkin, A. (2008). Exploring the relationship between employee creativity and job-related motivators in the Hong Kong hotel industry. International Journal of Hospitality Management, 27(3), 426-437.

Zhang, H. Q., \& Wu, E. (2004). Human resource issues facing the hotel and travel industry in China. International Journal of Contemporary Hospitality Management, 16(7), 424428. 
Figure 1

Conceptual Model

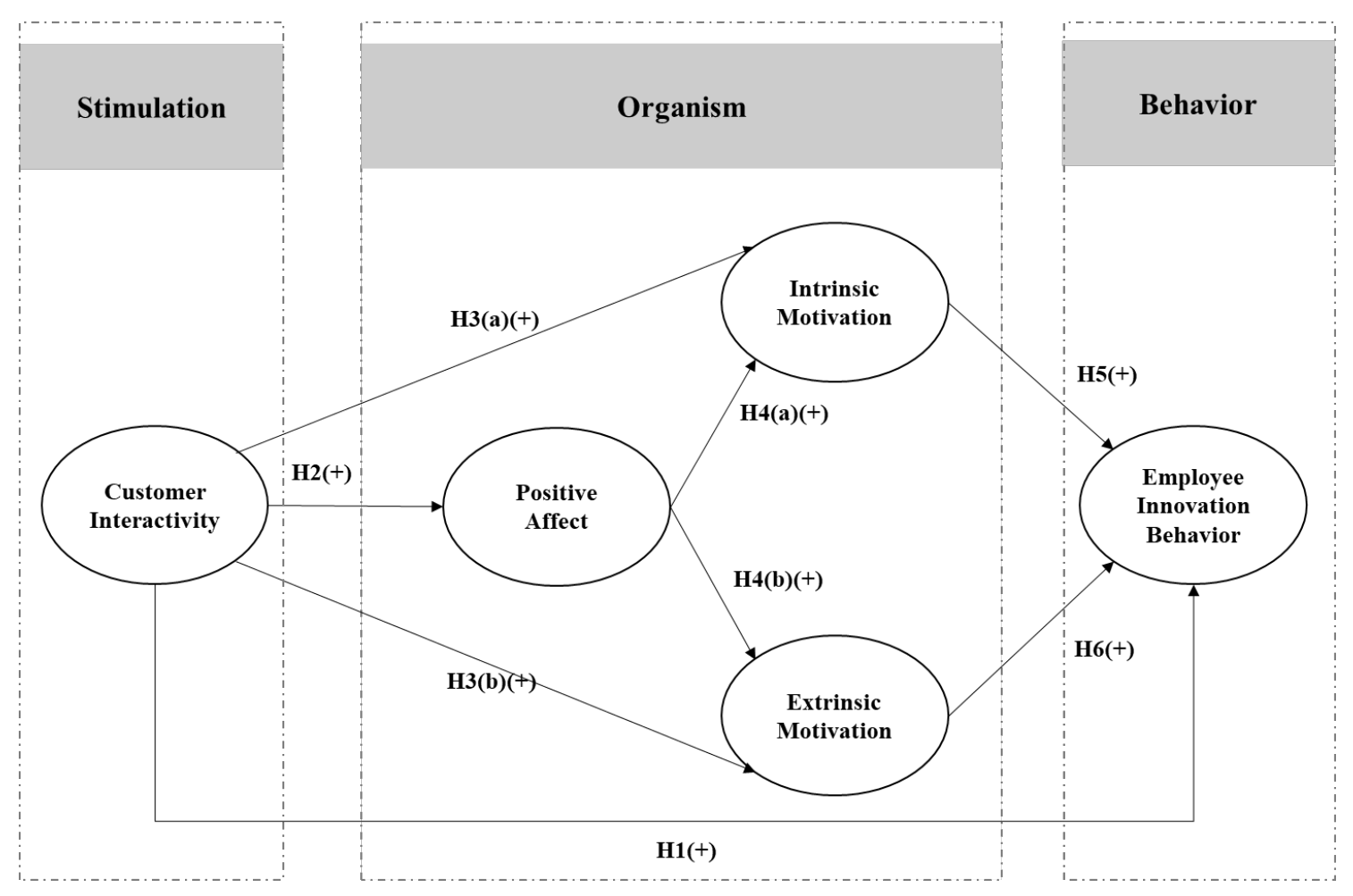


Table 1

Sample Profile

\begin{tabular}{|c|c|c|}
\hline Sociodemographic Variable & Frequency (n) & Percentage (\%) \\
\hline \multicolumn{3}{|l|}{ Gender $(\mathrm{n}=830)$} \\
\hline Male & 315 & 38.0 \\
\hline Female & 515 & 62.0 \\
\hline \multicolumn{3}{|l|}{$\operatorname{Age}(\mathrm{n}=830)$} \\
\hline$<=22$ & 243 & 29.3 \\
\hline $23-27$ & 132 & 15.9 \\
\hline $28-35$ & 186 & 22.4 \\
\hline $36-45$ & 182 & 21.9 \\
\hline $46-55$ & 74 & 8.9 \\
\hline$>55$ & 13 & 1.6 \\
\hline \multicolumn{3}{|l|}{ Education $(\mathrm{n}=830)$} \\
\hline Senior high school or below & 397 & 47.8 \\
\hline College & 367 & 44.2 \\
\hline Undergraduate & 60 & 7.2 \\
\hline Postgraduate & 6 & .7 \\
\hline \multicolumn{3}{|l|}{ Position(n=830) } \\
\hline Common staff & 624 & 75.2 \\
\hline Foreman/supervisor & 158 & 19.0 \\
\hline Manager & 48 & 5.8 \\
\hline \multicolumn{3}{|l|}{ Length in industry $(\mathrm{n}=830)$} \\
\hline$<1$ & 229 & 27.6 \\
\hline $1-2$ & 153 & 18.4 \\
\hline $3-5$ & 215 & 25.9 \\
\hline $6-10$ & 140 & 16.9 \\
\hline$>10$ & 93 & 11.2 \\
\hline
\end{tabular}


Table 2

\section{Estimated Measurement Model}

\begin{tabular}{|c|c|c|c|c|}
\hline Construct and Item & SFL & t value & $\mathrm{CR}$ & AVE \\
\hline Customer Interactivity $($ Mean $=5.41, S D=1.08)$ & & & 0.91 & 0.53 \\
\hline Communication between customers and service employees flowed frequently in both directions. & 0.63 & 19.49 & & \\
\hline Information was exchanged openly between customers and service employees. & 0.74 & 23.94 & & \\
\hline Service employees had extensive face-to-face interactions with customers. & 0.79 & 26.45 & & \\
\hline Customers interacted with service employees often in group discussions. & 0.70 & 22.46 & & \\
\hline Customers were highly involved in activities at the hotel. & 0.63 & 19.46 & & \\
\hline Customers and service employees worked together on problems. & 0.67 & 20.98 & & \\
\hline Issues were critically discussed between customers and service employees. & 0.82 & 28.191 & & \\
\hline Solutions were jointly developed between customers and service employees. & 0.82 & 27.61 & & \\
\hline Customers had many opportunities to evaluate services and products at the hotel. & 0.74 & 24.04 & & \\
\hline Positive Affect $($ Mean $=6.28, S D=.86)$ & & & 0.90 & 0.75 \\
\hline When I remember delightful service encounters, I feel enthusiastic about my work. & 0.85 & 29.14 & & \\
\hline When I remember delightful service encounters, I feel delighted about my work. & 0.93 & 33.34 & & \\
\hline When I remember delightful service encounters, I feel excited about my work. & 0.81 & 27.44 & & \\
\hline Intrinsic Motivation $($ Mean $=6.27, S D=.77)$ & & & 0.76 & 0.52 \\
\hline When I do work well, it gives me a feeling of accomplishment. & 0.67 & 20.21 & & \\
\hline I feel a great sense of personal satisfaction when I do my job well. & 0.72 & 21.95 & & \\
\hline When I perform my job well, it contributes to my personal growth and development. & 0.76 & 23.37 & & \\
\hline Extrinsic Motivation $($ Mean $=5.75, S D=.82)$ & & & 0.87 & 0.57 \\
\hline I am keenly aware of the goals I have for myself. & 0.80 & 26.57 & & \\
\hline I am strongly motivated by the recognition I can earn from other people. & 0.73 & 23.16 & & \\
\hline
\end{tabular}


I want other people to find out how good I really can be at my work.

$\begin{array}{ll}0.75 & 24.43 \\ 0.75 & 24.57 \\ 0.73 & 23.39\end{array}$

To me, success means doing better than other people.

Employee Innovative Behavior (Mean $=5.69, S D=.93)$

At work, I come up with innovative and creative notions.

At work, I try to propose my own creative and convince others.

At work, I seek new service technique, methods or technique.

At work, I provide a suitable plan for developing new ideas.

At work, I try to secure the funding and resources needed to implement innovation.

$0.78 \quad 25.78$

Overall, I consider myself a creative member of my team.

$0.73 \quad 23.98$

Note: $\mathrm{SFL}=$ Standardized factor loading, $\mathrm{CR}=$ construct reliability, $\mathrm{AVE}=$ average variance extracted. 
Table 3

Latent Variable Correlation Matrix

\begin{tabular}{llllll}
\hline Construct & 1 & 2 & 3 & 4 & 5 \\
\hline 1. Customer Interactivity & .73 & & & & \\
2. Positive Affect & $.26^{*}$ & .87 & & & \\
3. Intrinsic Motivation & $.31^{* *}$ & $.44^{* *}$ & .72 & & \\
4. Extrinsic Motivation & $.47^{* *}$ & $.43^{* *}$ & $.69^{* *}$ & .76 & \\
5. Employee Innovative Behavior & $.58^{* *}$ & $.39^{* *}$ & $.50^{* *}$ & $.64 * *$ &. $\mathbf{7 8}$ \\
\hline
\end{tabular}

Note: Boldfaced diagonal elements are the square root of AVE values. Off-diagonal elements are the correlations between constructs. ${ }^{* *} p<.01 .{ }^{*} p<.05$. 
Table 4

Estimated Structural Model

\begin{tabular}{|c|c|c|c|}
\hline Hypothesized Paths & Standardized Estimates & $\mathrm{t}$ values & Hypotheses Testing Results \\
\hline $\mathrm{EIB} \leftarrow \mathrm{CI}$ & $.27 * * *$ & 8.40 & $\mathrm{H} 1_{\mathrm{a}}$ : supported \\
\hline $\mathrm{PA} \leftarrow \mathrm{CI}$ & $.20 * * *$ & 6.65 & $\mathrm{H} 2_{\mathrm{a}}$ : supported \\
\hline $\mathrm{IM} \leftarrow \mathrm{CI}$ & $.17 * * *$ & 7.26 & H3(a)a: supported \\
\hline $\mathrm{EM} \leftarrow \mathrm{CI}$ & $.34 * * *$ & 11.79 & H3(b)a: supported \\
\hline $\mathrm{IM} \leftarrow \mathrm{PA}$ & $.38 * * *$ & 11.08 & H4(a)a: supported \\
\hline $\mathrm{EM} \leftarrow \mathrm{PA}$ & $.41 * * *$ & 11.24 & H4(b)a: supported \\
\hline $\mathrm{EIB} \leftarrow \mathrm{IM}$ & $.22 * * *$ & 4.16 & H5 a: supported \\
\hline $\mathrm{EIB} \leftarrow \mathrm{EM}$ & $.47 * * *$ & 11.14 & H6 $6_{a}$ : supported \\
\hline Indirect Effects & Standardized Estimates & SE & $95 \% \mathrm{BCa} \mathrm{CI}$ \\
\hline $\mathrm{IM} \leftarrow \mathrm{PA} \leftarrow \mathrm{CI}$ & $.13 * * *$ & .03 & {$[.08, .18]$} \\
\hline $\mathrm{EM} \leftarrow \mathrm{PA} \leftarrow \mathrm{CI}$ & $.10^{* * *}$ & .02 & {$[.06, .15]$} \\
\hline $\mathrm{EIB} \leftarrow \mathrm{IM} \& \mathrm{EM} \leftarrow \mathrm{PA} \leftarrow \mathrm{CI}$ & $.30 * * *$ & .03 & {$[.24, .37]$} \\
\hline
\end{tabular}

Note: $\mathrm{CI}=$ Customer Interactivity; $\mathrm{PA}=$ Positive Affect; $\mathrm{IM}=$ Intrinsic Motivation; EM=Extrinsic Motivation; $\mathrm{EIB}=$ Employee Innovative Behavior; $\mathrm{SE}=$ Standard Error; $\mathrm{BCa} \mathrm{CI}=$ the bias-corrected and accelerated confidence interval. Goodness-of-fit statistics: $\chi 2=1544.32, \mathrm{df}=408, \chi 2 / \mathrm{df}=3.79, \mathrm{p}<.01$, GFI $=.89$, CFI $=.92, \mathrm{NFI}=.90, \mathrm{TLI}=.91, \mathrm{RMSEA}=.06, \mathrm{SRMR}=.05 . \mathrm{EIB} \leftarrow \mathrm{PA} \leftarrow \mathrm{IM} \& \mathrm{EM} \leftarrow \mathrm{CI}$ means the mediating effect of positive affect, intrinsic motivation and extrinsic motivation between customer interactivity and employee innovative behavior. The other two relationships (IM $\leftarrow \mathrm{PA} \leftarrow \mathrm{CI}$ and $\mathrm{EM} \leftarrow \mathrm{PA} \leftarrow \mathrm{CI}$ ) also represent mediating effects; Results were based on a 1,000-bootstrap sample; A mediation path is significant if $\mathrm{BCa}$ CI does not contain the value of zero (Hayes, 2013). ${ }^{* * *} p<.001 .{ }^{* *} p<.01 .{ }^{*} p<.05$. 